\title{
As representações sociais sobre a velhice na perspectiva dos usuários de uma instituição de longa permanência
}

\author{
Patrícia Augusta Pospichil Chaves Locatelli ${ }^{1}$
}

\section{Resumo}

O envelhecimento da população brasileira tem demandado atenção, principalmente, no que tange ao cuidado para com o público idoso. Apesar de a legislação brasileira estabelecer que esta responsabilidade é de competência primordial da família, a dinamicidade do contexto social e a atual fluidez dos relacionamentos familiares têm implicado alterações nessa obrigatoriedade. Nesse contexto, as Instituições de Longa Permanência para Idosos (ILPIs) oferecem serviços de assistência social e à saúde, prioritariamente, para idosos que não possuem família ou quando essa não apresenta condições para assumir seu cuidado. Tendo-se presente o fato de que, muitas vezes, as instituições asilares são rotuladas pela sociedade de maneira preconceituosa, este estudo buscou identificar e analisar as representações sociais de idosos institucionalizados sobre a velhice e sobre a sua condição de idoso. Nesta pesquisa qualitativa, adotou-se o método de estudo de caso. A coleta de dados foi operacionalizada por meio de observação, entrevistas com idosos institucionalizados e classificação de imagens. Os resultados do estudo apontaram representações sociais distintas: algumas com foco nas perdas, na qual a velhice foi associada a abandono, solidão, conflitos, pobreza e doença, e ou- tras com foco nos ganhos, a exemplo das representações da velhice como uma fase ativa, propícia a envolvimentos amorosos e ao descanso.

Palavras-chave: Idosos. Instituições de Longa Permanência para Idosos. Representações Sociais. Velhice. Idosos. Instituições de Longa Permanência para Idosos.

\section{Introdução}

Devido ao crescimento do grupo populacional idoso, a temática velhice e o processo de envelhecimento humano vêm ganhando espaços cada vez maiores no cenário nacional ao longo da segunda metade do século XX. Nas últimas décadas, têm-se presenciado no Brasil não apenas um aumento no número de pessoas que passam a integrar o segmento idoso - formado por indivíduos com idade igual ou superior a 60 anos -, mas também o crescimento do grupo de sujeitos com 80 anos ou mais de idade, considerado muito idoso. O expressivo aumento da longevidade aponta para a

1 Graduada em Secretariado Executivo Trilíngue (Ulbra). Mestre em Administração (PPGA/Ufrgs). Doutoranda em Administração (PPGA/Ufrgs). Endereço para correspondência: Rua Padre Jobim, 260, Bairro Monte Belo, Gravataí - RS, 94055-100. E-mail: patriciaposp@gmail.com

$\rightarrow$ http://dx.doi.org/10.5335/rbceh.v13i2.6107

Recebido em: 14.06.2017. Aceito em: 03.07.2017. 
necessidade de se compreender a velhice e suas consequências não apenas no âmbito individual, mas também sob a perspectiva social.

O super envelhecimento da população brasileira associado a fenômenos como a mobilidade das famílias, a reestruturação dos arranjos familiares e a alteração no papel social da mulher têm reflexo direto no aumento da demanda por cuidados institucionais. As Instituições de Longa Permanência para Idosos (ILPIs) surgem como uma alternativa para suprir essa demanda, oferecendo ao público longevo serviços de assistência social e à saúde, principalmente, em casos em que o idoso não possui família, ou esta não apresenta condições para assumir a responsabilidade pelo seu cuidado.

Partindo-se da noção que preconiza o fato de as representações sociais só granjearem entendimento se forem estudadas à luz do contexto social em que estão inseridas e de onde emergem, bem como da influência que elas exercem sobre o comportamento e as ações dos indivíduos, têm-se as representações de senso comum que atribuem às ILPIs uma noção preconceituosa e de resistência quanto ao uso dos seus serviços por parte da sociedade ao associá-las a um lugar de exclusão e abandono de idosos. Diante desse quadro, o presente estudo buscou identificar e analisar as representações sociais de idosos institucionalizados sobre a velhice e sobre a sua condição de idoso.

Para atingir ao objetivo propugnado, o artigo está estruturado em oito seções, incluindo esta introdução. Primeiramente, elucida-se o que vêm a ser representações sociais. As seções três e quatro abordam teoricamente a velhice sob dois modelos antagônicos e as instituições de longa permanência para idosos. Posteriormente, são apresentados o método e a análise dos resultados do estudo, culminando com as considerações finais e indicações para estudos futuros.

\section{As representações sociais desde uma perspectiva teórica}

"Representação social corresponde a um conceito que permite o descortinamento do simbólico em um dado contexto cultural" (CAVEDON, 2003, p. 101). Esta teoria - cujo objeto de investigação são os modos sociais de representação do mundo (VALSINER, 2015) - está vinculada à ordem do simbólico, uma vez que determinados elementos, sejam materiais ou imateriais, podem apresentar significados distintos a depender da cultura do grupo social que o esteja significando (CAVEDON, 2005; ROWLAND, 1996). As representações sociais pertencem a um universo diferente de conhecimento, por exemplo, do da cognição social, do estudo das opiniões, das atitudes, dos preconceitos, entre outros (MARKOVÁ, 2015).

A origem das representações situa-se nos processos de comunicação (JOVCHELOVITCH, 2011; VALSINER, 2015) e nas práticas sociais, como o diálogo, o discurso, os rituais, os padrões de trabalho e produção, a arte e a cultura (JOVCHELOVITCH, 2011). É por meio 
da ação dos indivíduos, atuando em um espaço comum a todos, que um grupo social desenvolve e sustenta saberes sobre si mesmo, ou seja, representações sociais (JOVCHELOVITCH, 2011).

As representações perpassam determinada sociedade como algo anterior e habitual, reproduzido e modificado a partir das estruturas e das relações coletivas, não sendo, necessariamente, um processo consciente (MINAYO, 2011). Todavia, não correspondem a meras abstrações, uma vez que elas funcionam também como orientadoras das práticas sociais (VICTORA; KNAUTH; HASSEN, 2000). As representações sociais são criadas com a finalidade de regular as relações, ou seja, ajustar os indivíduos ao mundo à sua volta, para que saibam como se comportar, como dominá-lo física e intelectualmente, identificando e resolvendo os problemas que se apresentam (JODELET, 2001; 1986; ROWLAND, 1996; VALSINER, 2015).

A diversidade das representações sociais pode ser identificada a partir da divisão da sociedade em comunidades ou grupos sociais menores e, também, por sua característica circular que faz com que as representações sejam ressignificadas (ARRUDA, 2015; LOCATELLI, 2012). O próximo item revela essa diversidade ao mostrar distintas noções atribuídas à velhice, sendo que, em certos momentos, essas perspectivas apresentam pontos divergentes e antagônicos.
Velhice: "Terreno propício a ambiguidades"

As representações sobre a velhice, ou seja, a posição que os indivíduos mais velhos ocupam na sociedade e o modo como são tratados refletem as formas como são distribuídas e significadas as diferenças etárias, variando de acordo com os contextos históricos, sociais e culturais (DEBERT, 1999; GROISMAN, 1999; TAVARES, 2015). Os sentimentos em relação a esta etapa da vida são carregados de valor, podendo oscilar entre a aceitação e a rejeição, a valorização e a negação, o respeito e a desvalorização, razão pela qual Neri (2007) explica a velhice como um terreno propício a ambiguidades.

O envelhecimento é um processo que engloba constantes transformações que podem ser interpretadas simultaneamente como ganhos e perdas (LOCATELLI; CAVEDON, 2012; TORELLY, 2010). Por conseguinte, o debate sobre o envelhecimento apresenta basicamente duas visões antagônicas.

Vista como uma consequência natural do processo de envelhecimento (NUNES, 2010; PAPALÉO NETTO, 2016; 2011; SOUZA, 2010; SOUZA; MATIAS; BRETAS, 2010), a velhice tem sido comumente associada a perdas, impotência, decrepitude, desajuste social, pauperização, inatividade, improdutividade, entre outros (HENDY, 2015; PASCHOAL, 2011; SOUZA; MATIAS; BRETAS, 2010). Nesta etapa, é corrente atribuir-se à população idosa características como dependência e vulnerabilidade em relação 
às suas capacidades para administrar as atividades cotidianas e de trabalho (CAMARANO, 2004; PAPALÉO NETTO, 2011).

Nesse sentido, esta fase da vida estaria relacionada à saída das atividades econômica e produtiva, com níveis crescentes de morbidade devido a doenças crônico-degenerativas, com mudanças na aparência física e com perda de papéis sociais e de autonomia (CAMARANO, 2004; PAPALÉO NETTO, 2011). A partir desse entendimento, os idosos são vistos como um grupo homogêneo, dotados dos mesmos atributos, qualidades e potencialidades, não distintos uns dos outros e relegados a uma existência sem significado (DEBERT; SIMÕES, 2011; ROSA; BARROSO; LOUVISON, 2013). Essa concepção de envelhecimento se opõe a que considera a velhice de um modo mais positivo, exaltando os ganhos que podem ser auferidos nesta etapa da vida (BULLA; MEDIONDO, 2010).

$\mathrm{O}$ que difere a segunda perspectiva da visão negativa de velhice é a caracterização de uma fase privilegiada de vida em que as pessoas aproveitariam seu tempo intensamente, em busca de realizações pessoais (GROISMAN, 1999; ROSA; BARROSO; LOUVISON, 2013). Nessa ótica, os indivíduos idosos - considerados ativos, saudáveis e capazes, que redefinem sua experiência de forma a se contrapor aos estereótipos ligados à velhice (DEBERT, 2010; 1999; LOPES, 2007) - têm perspectivas de futuro (LOPES, 2007). O idoso bem-sucedido é comumente representado por indivíduos dinâmicos com tempo e recursos para realizar novos projetos e usufruir de diversão e liberdade, que mantêm sua funcionalidade, flexibilidade e adaptabilidade frente aos desafios advindos do envelhecimento (ALCÂNTARA, 2004; DEBERT, 1999; FERREIRA; CUNHA; MENUT, 2008).

Nessa forma de pensar, o envelhecer com qualidade de vida e bem-estar ocorre quando as pessoas se reorganizam, mantendo a independência e um envolvimento ativo com a vida pessoal, a família, os amigos e a vida social, desenvolvendo novos projetos e relacionamentos como forma de compensar o que foi perdido em função da idade (FRAQUELLI, 2010; TORELLY, 2010; NOVAES, 1997). A velhice bem-sucedida não nega as perdas, mas enfoca a capacidade de adaptação dos indivíduos tanto nos aspectos biológicos quanto nos psicológicos e sociais (FERREIRA; GOULART, 2010; NUNES, 2010; SOUZA; MATIAS; BRETAS, 2010; VARGAS; TACQUES, 2010).

Com vistas a clarificar o universo das ILPIs, contexto social no qual estão inseridos os participantes deste estudo, o próximo item apresenta um esboço do que vem a ser uma ILPI, sua origem, função e os preconceitos associados a essa modalidade de cuidado.

\section{As instituições de longa permanência para idosos}

Nas duas últimas décadas, a institucionalização de idosos vem merecendo atenção no Brasil devido ao envelhecimento de sua população e, consequentemente, à busca de alternativas que 
supram as necessidades advindas desse fenômeno. Uma possibilidade para o cuidado não familiar são as Instituições de Longa Permanência para Idosos (CAMARANO; BARBOSA, 2016; CAMARANO; KANSO, 2010; CAMARANO et al., 2010).

As ILPIs são instituições governamentais ou não governamentais, de caráter residencial, destinadas ao domicílio coletivo de pessoas com idade igual ou superior a 60 anos, com ou sem suporte familiar, em condição de liberdade, dignidade e cidadania (ANVISA, 2005). As ILPIs caracterizam-se como instituições de função híbrida, pois, além dos serviços voltados aos atendimentos clínico e terapêutico, oferecem aos residentes moradia, alimentação, vestuário, atividades de ocupação e lazer, entre outros (CAMARANO; BARBOSA, 2016; CAMARANO; KANSO, 2010; CAMARANO et al., 2010; HERÉDIA; CORTELETTI; CASARA, 2010).

Apesar de ser a modalidade de cuidado mais comum ao idoso dependente fora do âmbito familiar em todo o mundo, no Brasil, a institucionalização de idosos ainda não se transformou em uma prática plenamente aceita. As instituições asilares costumam ser alvo de preconceito e resistência por parte da sociedade que as associa a depósito de velhos, lugar de exclusão, dominação e isolamento social, ou ainda, lugar para morrer (CAMARANO; KANSO, 2010; CAMARANO et al., 2010; CHRISTOPHE; CAMARANO, 2010).

Parte do preconceito pode encontrar justificativa na história da instituciona- lização da velhice que iniciou como uma prática assistencialista (ALCÂNTARA, 2004; BERZINS; GIACOMIN; CAMARANO, 2016; CAMARANO; BARBOSA, 2016; CAMARANO; KANSO, 2010; CHRISTOPHE; CAMARANO, 2010) e na associação comum de ILPIs a instituições totais (GOFFMAN, 2003). A esses preconceitos se somam: o medo da morte e da finitude experimentado pelas pessoas; as denúncias de violência praticadas nas instituições e veiculadas na mídia; as condições precárias e a baixa qualidade dos serviços prestados por algumas instituições (ALCÂNTARA, 2004; CAMARANO; BARBOSA, 2016; CHRISTOPHE; CAMARANO, 2010; LOPES, 2007). Tais preconceitos apresentam uma barreira à institucionalização de idosos (CAMARANO et al., 2010) e podem influenciar na imagem que se cria a respeito da velhice. No próximo item, é apresentado o método que permitiu a obtenção dos dados, visando a atingir o objetivo proposto.

\section{Procedimentos metodológicos}

Em relação aos procedimentos metodológicos, foi desenvolvida uma pesquisa qualitativa (CAVEDON, 2005), cujo método foi o estudo de caso, no período compreendido entre setembro de $2011 \mathrm{e}$ fevereiro de 2012, em uma ILPI de natureza filantrópica localizada na cidade de Porto Alegre - RS. A escolha da ILPI considerou os seguintes critérios: a) ser uma instituição de grande porte; e b) ter usuários pertencentes a camadas populares. 
Para este estudo, buscou-se a participação de idosos com 75 anos ou mais de idade. Ao todo, oito idosos foram convidados a participar da pesquisa. Três se recusaram sob a justificativa de estarem indispostos. Assim sendo, o estudo con- tou com a participação de cinco usuários - três idosas e dois idosos -, com idades entre 79 e 86 anos. A Tabela 1 apresenta o perfil dos participantes - referenciados no estudo por nomes fictícios.

Tabela 1 - Perfil dos participantes

\begin{tabular}{c|c|c|c|c}
\hline Sujeito & Gênero & Idade & Estado Civil & Tempo na instituição \\
\hline Sr. João & M & 83 & Viúvo & 6 meses \\
D. Helga & F & 86 & Viúva & 4 anos \\
D. Noêmia & F & 79 & Solteira & 5 meses \\
D. Rosalina & F & 82 & Casada & 3 anos \\
Sr. Valdomiro & M & 83 & Viúvo & 6 meses \\
\hline
\end{tabular}

Fonte: elaborado pela autora.

No que se refere à coleta e à análise de dados, não existe uma técnica específica da Teoria das Representações Sociais, mas uma variedade de técnicas, como entrevistas, observação, grupos focais, entre outras (SÁ, 1998; SILVA; CARRIERI, 2014). A partir das técnicas escolhidas, busca-se observar a tentativa dos sujeitos de familiarizar-se com algo que lhes é estranho (CAVEDON, 1999). Neste estudo, as técnicas de coleta de dados adotadas foram: a) observação simples, com registro em diários de campo; b) entrevistas semiestruturadas; e c) classificação de imagens - técnica de trabalho que consiste em apresentar aos participantes da pesquisa diferentes imagens e solicitar que as selecionem ou ordenem de acordo com a proposta da pesquisa (VICTORA; KNAUTH; HASSEN, 2000).

Para este estudo, foram selecionadas 18 imagens de indivíduos idosos em diferentes locais e condições físicas e sociais. As imagens foram impressas como fotografia em tamanho $20 \times 30$ $\mathrm{cm}$ e intercaladas de modo a mesclar mensagens a respeito da velhice que poderiam ser interpretadas como positivas ou negativas. Em um primeiro momento, foi solicitado aos participantes que escolhessem três imagens que melhor refletissem sua opinião sobre os idosos da ILPI e relatassem o motivo da escolha. Em um segundo momento, foi solicitado aos idosos a escolha de uma única imagem que refletisse sua opinião sobre o envelhecimento na sociedade de modo geral. $\mathrm{O}$ objetivo dessa técnica foi conhecer as representações e os valores que os participantes atribuíam às imagens selecionadas.

As entrevistas e o processo de escolha das imagens foram gravados em áudio, seguidos de transcrição e registros feitos em diários de campo. A escolha do local para a realização das entrevistas respeitou a preferência dos participantes, 
a saber: no pátio (Sr. João, D. Helga e D, Noêmia), no quarto (D. Rosalina) e no refeitório (Sr. Valdomiro).

Para análise dos dados coletados, partiu-se da perspectiva das representações enquanto produto (SPINK, 2004) - quando a pesquisa busca compreender os elementos constituintes das representações (informações, imagens, opiniões, etc.), devendo ser analisadas com base no contexto no qual emergem, circulam e se transformam (MARQUES, 2011). Após a escuta das entrevistas e a leitura das transcrições e diários de campo, o material foi explorado, partindo-se de duas categorias temáticas (BARDIN, 2010; GOMES, 2011) - a das representações positivas e a das representações negativas sobre a velhice. Posteriormente, foram elaboradas subcategorias, a partir das representações recorrentes (CAVEDON, 2014).

Com relação aos aspectos éticos, a autorização para a realização desta pesquisa na ILPI foi formalizada por meio do "Termo Institucional de Consentimento Informado". Depois de esclarecidos quanto aos objetivos da pesquisa, foi solicitado aos idosos participantes a assinatura do "Termo de Consentimento Livre e Esclarecido". O projeto de pesquisa foi registrado no Sistema Pesquisa da Universidade Federal do Rio Grande do Sul (Ufrgs), sob o número 21401. Após análise da Comissão de Pesquisa da Escola de Administração da Ufrgs, o projeto foi encaminhado ao Comitê de Ética em Pesquisa da mesma intituição, obtendo parecer favorável no dia 08 de setembro de 2011.

As próximas seções apresentam as significações que os participantes atri- buem à velhice. Inicialmente, são apresentadas e analisadas as representações negativas - com foco nas perdas - e, posteriormente, as representações positivas - com foco nos ganhos.

\section{Representações sociais sobre a velhice: foco nas perdas}

\section{A velhice como a fase do abandono e da solidão}

O processo de asilamento de idosos ocorre de forma heterogênea, uma vez que reflete situações diversas. Algumas são impostas pela vida, como a situação socioeconômica e demográfica da família, desentendimentos geracionais, aparecimento de doenças geradoras de dependência física ou psíquica, ou por vínculos que se desfizeram, a exemplo da perda de familiares e amigos (BERZINS; GIACOMIN; CAMARANO, 2016; CAMARGOS et al., 2016; HERÉDIA; CORTELETTI; CASARA, 2010), como relatado pela D. Noêmia (79 anos de idade): "Perdi meu pai, perdi minha mãe, perdi meu irmão, perdi minha irmã. Deus levou tudo e só me deixou".

A existência de família não assegura que o idoso seja amparado no âmbito domiciliar, pois nem todas as famílias estão preparadas para assumir o papel de cuidadoras. Esse suporte familiar aos idosos torna-se reduzido por fatores ligados à mobilidade das famílias, ao seu tamanho, ao crescente número de divórcios e à situação da mulher que ingressou no mercado de trabalho, transformando os contratos tradicionais de gênero (AL- 
CÂNTARA, 2004; CAMARANO; BARBOSA, 2016; CAMARANO; KANSO, 2010; HERÉDIA; CORTELETTI; CASARA, 2010). Essa realidade se revela no depoimento do Sr. João (83 anos de idade) ao enunciar o motivo de sua institucionalização: "Vim pra cá porque a minha filha e o meu genro trabalham, eu ficava em casa sozinho, sem comida".

A institucionalização pode representar uma alternativa de amparo, proteção e segurança, além de uma oportunidade para a formação de novos vínculos com outros idosos e cuidadores (CAMARANO; BARBOSA, 2016; CHRISTOPHE; CAMARANO, 2010). Entretanto, entende-se que esse mesmo processo pode representar o início da solidão, pois muitas famílias têm utilizado essa alternativa de cuidado para transferir a terceiros, nesse caso à ILPI, a responsabilidade por seu familiar idoso. "Aí, ela deu aquela desculpa: 'É, mãe! Porque a senhora não pode mais ficar sozinha, porque a senhora é doente e pode dar qualquer coisa aí.' Eu não sou boba não. Isso aí foi uma traição que ela fez pra mim” (D. Rosalina, 82 anos).

O processo de institucionalização não vem acompanhado de um projeto de retorno à comunidade e à família e pode, em muitos casos, formalizar o abandono previamente constituído no ambiente familiar (CAMARANO; BARBOSA, 2016). $\mathrm{O}$ caso da D. Helga (86 anos de idade) é revelador. Tendo por justificativa "dar um descanso" aos familiares, ela afirma: "Eu estava incomodando. Chega num ponto que tu estás notando que está enchendo o saco". A fala traz à tona a ideia de que a velhice acarreta ao idoso a perda de espaço e de autoridade, evidenciando a influência da dinâmica familiar no processo de institucionalização (LOCATELLI; OLIVEIRA; CAVEDON, 2014). Para Novaes (1997), com a velhice o indivíduo passa a ocupar um lugar ambíguo no território doméstico. Se, por um lado, ele é exigente e autoritário, lutando por se afirmar e por manter seu status, por outro, ele é fraco, dependente, sem iniciativa, sente-se magoado pela perda de seu prestígio, não colabora, acarretando mais despesas e preocupações.

\section{A velhice como a fase dos conflitos}

Durante a realização da pesquisa, foi possível observar o comportamento de alguns idosos que frequentemente reclamam, xingam e agridem, expressando por meio dessas ações a revolta relacionada com sua atual condição de vida. Novaes (1997) justifica tais comportamentos como uma consequência do sofrimento causado pelo abandono por parte da família. Entretanto, o comportamento dos idosos não está apenas atrelado à realidade da institucionalização e do abandono. Herédia, Corteletti e Casara (2010) ressaltam que, ao ingressar na ILPI, o idoso traz consigo uma bagagem sustentada nas relações estabelecidas com a família e com o meio em que vivia. Essa bagagem vem carregada com as experiências vivenciadas, a exemplo do casamento, do nascimento de filhos, da aposentadoria, da perda do (a) companheiro (a), dentre tantas outras situações. 
A maioria dos participantes mostrou concordar com a representação social de que o idoso é de difícil trato ao falar a respeito dos demais idosos e de si mesmo. "Eu já larguei de mão. Não me misturo com ninguém, não faço amizade com ninguém. Porque não dá. Não dá pra fazer amizade porque é só fofoca, é só diz-que-me-diz-que, é esse e esse e aquele e aquele outro e assim" (D. Rosalina, 82 anos de idade). Essa representação vai ao encontro de Debert (1999), que acredita que os idosos também podem ser tiranos, chatos e indiscretos, pois o avanço da idade não garante um comportamento adequado.

As brigas entre os usuários, principalmente entre as mulheres idosas, constituem o cotidiano da ILPI pesquisada. Chama atenção o fato de que, muitas vezes, as brigas entre idosos ultrapassam $o$ âmbito verbal. As agressões podem ser físicas, com o uso inclusive de objetos pessoais, como as bengalas. Brigas entre os homens institucionalizados não são tão frequentes, provavelmente porque eles representam a minoria, não atingindo $30 \%$ do número total de moradores. Embora caracterizem acontecimentos raros, quando ocorrem, as brigas entre homens tendem a ser mais violentas.

Uma das opções que a instituição dispõe para a resolução de conflitos é o remanejamento dos idosos para outros quartos. Entretanto, essa ação se mostra limitada pela estrutura da instituição, que conta com apenas dois quartos individuais. É também uma alternativa paliativa, pois a insatisfação demonstrada pelos idosos que recebem o "remanejado" em seu quarto costuma resultar em novas brigas. Em casos extremos, a única alternativa cabível é o desligamento do idoso.

\section{A velhice como a fase da pobreza}

De acordo com Barros (1998), os traços estigmatizantes da velhice não necessariamente estão ligados à idade cronológica, pois estão mais relacionados a valores e conceitos depreciativos, tais como: feiura, doença, morte, desesperança, solidão, tristeza, inatividade, pobreza e falta de consciência de si e do mundo. Nesse sentido, a questão econômica constitui um fator determinante na construção de uma visão positiva ou negativa a respeito do envelhecimento (LOCATELLI, 2012).

A associação da velhice a um período em que o indivíduo se retrai frente à pobreza pode ser exemplificada pelo relato da D. Rosalina (82 anos) sobre sua atual fase de vida: "Eu não estou gostando nada, nada. De jeito nenhum! Eu trabalhava, tinha meu dinheiro, comprava o que eu queria. Era outra vida e agora virar nisso? Ah, não! Então, como é que vai ser feliz se eu dependo só dos meus filhos?".

Sendo a capacidade produtiva o que mensura o valor do homem na sociedade capitalista, contemporânea, moderna, o idoso é qualificado e se autoqualifica como marginalizado, pois, diante da perda de valor social e psicológico, ele não tem mais o que demandar, uma vez que já atingiu os potenciais evolutivos (LOPES, 2007). Essa dependência social 
se reflete no processo de reificação dos sujeitos na sociedade, não se limitando apenas aos idosos, mas a todos os indivíduos que não possuem um corpo eficiente para o trabalho e para a manutenção do sistema econômico (LOCATELLI; OLIVEIRA; CAVEDON, 2014). É por isso que as narrativas dos idosos sobre o processo de envelhecimento são articuladas em relação à precariedade da situação econômica dos indivíduos.

\section{A velhice como a fase das doenças}

Sabe-se que as limitações e a perda dos controles do corpo, dos controles emocionais e das habilidades cognitivas são algumas das consequências do processo de envelhecimento, entretanto, a sociedade pode supervalorizar a visão da velhice como exclusivamente um conjunto de perdas (DEBERT, 1999). Os relatos de dores e doenças foram frequentemente mencionados pelos idosos durante as entrevistas, nas quais as questões vinculadas à saúde e aos cuidados que necessitam emergiram em meio à discussão de outros assuntos. Tais declarações revelam a percepção dos entrevistados sobre a velhice, como uma fase marcada pelo surgimento de doenças.

A ideia de que a institucionalização traz consequências negativas aos idosos, ou seja, de que as patologias às quais a velhice está sujeita são aceleradas no contexto de asilamento (DEBERT, 1999), foi relatada por alguns dos participantes, como a D. Rosalina (82 anos de idade): "É pra tu vê como muda a coisa. Depois que caiu aqui, tá no que tá... mais pra lá do que pra cá, é o que eu estou te falando, a pessoa cai aqui, bah... Minha filha não gosta que eu fale. Agora, quem chega aqui pode só esperar a morte".

Para Herédia, Corteletti e Casara (2010), pela diminuição da capacidade de adaptação às agressões externas e internas, que os torna mais frágeis, os idosos têm maior propensão ao adoecimento. Segundo as autoras, a solidão e o baixo nível socioeconômico representam fatores geradores ou agravantes de problemas de saúde. $\mathrm{Na}$ opinião dos entrevistados, a transferência de idosos para a ala dos acamados significa a direta associação da fase de dependência à morte.

O medo da morte é um medo universal, compartilhado por todos os indivíduos, principalmente na fase da velhice (CAMARANO; BARBOSA, 2016; NOVAES, 1997). Entretanto, os idosos entrevistados revelaram não ter medo da morte, mas, sim, do sofrimento de se tornarem dementes ou dependentes. "A maioria se impressiona com a velhice. Eu não me impressiono com a velhice. Nasceu, viveu e vai morrer. Lógico que vai. Eu só peço a Deus, sabe, que não me faça assim esquecer. Eu quero é me lembrar de tudo" (D. Helga, 86 anos).

Para Barros (1998), a morte configura não apenas o fim da vida para os idosos, mas também a perda da consciência de si mesmos enquanto indivíduos. No estudo da referida autora, ficaram evidenciadas situações similares às apresentadas pelos usuários da presente pesquisa, que são o temor pela perda da consciência de si mesmos como seres 
pensantes e independentes, como pessoas capazes de se responsabilizarem pelas decisões tomadas. Como afirmam Figueiredo e Cavedon (2009), quando associada à decrepitude, à dependência de pessoas mais jovens e à iminência constante do abandono, a velhice se torna sinônimo de sofrimento.

\section{Representações sociais sobre a velhice: foco nos ganhos}

\section{A velhice ativa}

A ideia do idoso como indivíduo ativo foi apresentada por Debert (1999) como uma forma de romper com as tradicionais imagens negativas atribuídas à velhice. Essa visão se contrapõe aos estereótipos ligados a essa fase de vida, como a perda de ânimo ou a dificuldade em manejar o próprio corpo e lidar com essa situação. As vantagens na manutenção de uma vida ativa se estendem tanto ao aspecto físico quanto aos aspectos pessoais e sociais. A forma como as pessoas mais velhas continuam a participar ativamente nas questões sociais, econômicas, culturais, espirituais e civis determina o nível de sua qualidade de vida (ROSA; BARROSO; LOUVISON, 2013; TORELLY, 2010).

Entretanto, entre os usuários da instituição, há alguns que, mesmo apresentando condições físicas para participar das atividades propostas, optam por não se envolver, buscando alternativas outras para ocupar o tempo livre, como a D. Noêmia (79 anos de idade): "Ah!
Eu não sou ligada nessas coisas [festas, bingos, filmes]. Eu tenho minhas palavrinhas cruzadas. As coisas pra ler. Mas sempre muito quieta assim. Não sou de estar no meio do povo, de badalação"; e o Sr. João (83 anos de idade): "Ah, eu me ocupo muito, por exemplo, eu faço muitas orações comigo mesmo. Caminho orando. E me entretenho".

Os indivíduos mais introspectivos, que encontram satisfação numa vida mais contemplativa e com poucas atividades, como o Sr. João (83 anos de idade), podem também envelhecer bem, desde que aceitem a diminuição de seu mundo e se adaptem a ele (NOVAES, 1997). As representações sociais sobre o idoso ativo não estão relacionadas apenas às atividades de lazer, à disposição para o trabalho e aos cuidados com o corpo e a saúde. Nessa fase, o exercício da sexualidade também pode ser uma realidade.

\section{A velhice dos envolvimentos amorosos}

As questões que envolvem relações amorosas e sexualidade estão presentes no contexto institucional da ILPI pesquisada e no discurso dos idosos entrevistados. $\mathrm{O}$ casamento de idosos que se conheceram, namoraram e tiveram a união oficializada na instituição é uma das histórias mais reproduzidas. A lembrança e os relatos dos entrevistados revelaram a representação social que caracteriza o idoso como alguém que ainda tem "essa coisa de paixão" (LOCATELLI, 2012), em contradição a um dos mitos do envelhecimento que prediz a inexistência de interesse e desejo sexual nessa idade. 
No que se refere às experiências amorosas e às práticas sexuais, os idosos reproduzem dentro da instituição o mesmo que ocorre na sociedade de maneira geral: namoro, ciúmes, expectativa de casamento, relações extraconjugais, relações homossexuais, entre outros.

E eu disse pro meu esposo: Olha, eu não quero ficar igual a [...], namorando aí anos e anos. Digo, depois tem outra, nós não temos mais idade de ficar de namorico de quinze anos. Ou bem tu resolve casar ou tu vai cuidar da tua vida e eu cuido da minha [...]. Como eu estou te falando, não, meu coração não aceita. Isso aqui é namorico daqui, é amante de lá. Olha, não tem explicação. E outra que eu já estou com 82 , eu nunca tinha visto... as mulheres serem assim amigas das outras. Amiga da outra. Olha, como é que se diz: machorra. Igual a Xuxa com aquela outra (D. Rosalina, 82 anos).

O relacionamento entre idosos ainda é considerado incomum na sociedade brasileira. As ideias mais aceitas socialmente têm sido aquelas que afirmam que, ao atingirem a fase da velhice, os indivíduos perdem todo interesse sexual, tornando-se "puritanos", ou ainda que são "pervertidos", "sem-vergonha", "tarados" ou "assanhados", porque continuam a se relacionar sexualmente (ALCÂNTARA, 2004). Isso ocorre porque a norma dominante sobre a velhice percebe os idosos, principalmente as mulheres, como seres assexuados, entretanto, estudos, como os realizados por Alcântara (2004), Locatelli (2012), Motta (1998) Novaes (1997), comprovam o contrário.

\section{A velhice do merecido descanso}

$\mathrm{O}$ envelhecimento representa um processo, em que, com o passar do tempo, as capacidades vão cedendo espaço às limitações (KELLY; RIBAS; COSTA, 2010). Cada indivíduo elabora suas perdas e rupturas de modo subjetivo, por meio de vivências personalizadas. A percepção da velhice varia de acordo com contextos socioculturais, experiências e oportunidades de vida, sendo que fazem parte desse jogo: estados de saúde, circunstâncias familiares, sucessos e frustrações pessoais e profissionais (CAMARANO; KANSO, 2009; FERREIR; CUNHA; MENUT, 2008; NOVAES, 1997).

A visão a respeito do envelhecimento depende da filosofia de vida e dos valores pessoais e sociais. Se, para alguns, ele caracteriza um período vazio, sem valor, inútil, sem sentido; para outros, pode ser um tempo de liberdade, de ruptura com os compromissos profissionais, de desenvolvimento de atividades que o indivíduo não teve tempo para realizar, um momento de aproveitar a vida (KELLY; RIBAS; COSTA, 2010). É o que expressa a fala da D. Helga (86 anos de idade) que, após relatar uma vida de sofrimento e perdas, vê na velhice uma oportunidade para o descanso.

E agora eu quero descansar minha cabeça, né. Os filhos estão lá casados. Cada um tem a sua casa. Eu dei tudo pra eles e agora eu vou morrer... estão bem encaminhados. [...] Mas, estou gostando daqui. Eu tô achando bom, porque eu descanso. Não sou obrigada mais a ter que cuidar das lavadeiras, da empregada, ainda vê como está sendo a lim- 
peza da casa. Fazer aquela obrigação que eu tinha de dona de casa. Parece mentira. Com oitenta e dois anos eu me tornei independente! Não era independente. O miserável [marido] custou pra morrer. Depois, era pelotense. Pelo amor de Deus! Que gente triste, né? Eu estou bem. Papai do céu me deixou viva, né, pra aproveitar um tempinho depois da morte do desgraçado. [...] Agora eu estou livre. Eu quero aproveitar o que restou de mim. Por minha causa e não por causa dos outros (D. Helga, 86 anos).

A declaração da D. Helga pode ser compreendida pelo fato de a maioria das mulheres idosas nunca ter tido vida profissional ativa e por ter experimentado uma vida social e sexual muito mais restritiva e reprimida do que os homens da mesma geração, o que pode induzi-las a perceber esse estágio de vida de forma diferente da visão masculina (BARROS, 1998). Devido a esses fatores, as mulheres consideram essa etapa como um momento de tranquilidade, liberdade e felicidade em suas vidas (BARROS, 1998). Alcântara (2004) compartilha dessa mesma ideia ao afirmar que a liberdade constituiu um valor essencial na ressignificação da velhice, uma vez que a educação e o controle exercidos por pais e maridos impediam manifestações de liberdade.

\section{Considerações finais}

Este estudo buscou identificar e analisar as representações sociais de idosos institucionalizados sobre a velhice e sobre a sua condição de idoso. As representações sociais dos participantes a respeito da velhice emergiram principalmente nos relatos de experiências vivenciadas ao longo da vida e no cotidiano da instituição de longa permanência pesquisada, confirmando que as representações são fruto do contexto social experimentado. As noções elaboradas pelos participantes perpassaram as duas visões antagônicas de velhice, uma com foco nas perdas e outra com foco nos ganhos. Todavia, os modelos de envelhecimento apresentados não esgotam as discussões e as diferentes visões sobre o tema.

Este estudo não intencionou limitar a visão a respeito da velhice entre "pobre doente e infeliz" versus "rico saudável e feliz", visto que as perdas físicas e mentais assim como os sentimentos de abandono e solidão podem atingir a todos os idosos, independentemente de classe social. Em função de limitações temporal e espacial, foram consideradas no estudo as representações sociais mencionadas pela maioria dos participantes. Entretanto, outras representações emergiram em caráter particular e apontam para a possibilidade de prosseguimento de pesquisas sobre o tema. Admite-se ainda a existência das mais distintas representações sociais a respeito dessa etapa de vida, originárias de realidades não consideradas neste estudo, limitado a um contexto específico de institucionalização, como, por exemplo, casos em que os idosos atuam como provedores do sustento familiar ou ainda como responsáveis pelas atividades domésticas e pelo cuidado com os netos.

Do ponto de vista da gestão, entende-se que os desafios das ILPIs não estão relacionados apenas à acolhida de indivíduos idosos, estendendo-se à compre- 
ensão da heterogeneidade do processo de envelhecimento e das expectativas, necessidades e reivindicações dos idosos que não podem ser tratados como um grupo homogêneo. As instituições de longa permanência para idosos devem trabalhar ao nível do simbólico, ressignificando a noção de idoso e, se necessário, reestruturando as políticas de atendimento adotadas em relação aos usuários.

Isso porque, dependendo da representação social que têm do idoso, embasadas no modelo com foco nas perdas ou no modelo com foco nos ganhos, as instituições podem dirigir suas práticas para ações que resultam na desvalorização ou na valorização dessa população. Por essa razão, sugere-se, para estudos futuros, o cruzamento das representações de idosos institucionalizados com as de trabalhadores, gestores e voluntários que atuam nessas instituições, visto que esse pode revelar aspectos convergentes e divergentes que acabam por afetar a gestão da instituição e merecem ser explorados.

\section{The social representations about old age in view of users of an long term care institution}

\section{Abstract}

The aging of the population has demanded attention, especially with regard to care for the elderly public. Although Brazilian law establish that this responsibility is of primary competence of the family, the dynamics of the social context and the current fluidity of family relationships have involved changes to that obligation. In this context, the Long Term Care Institutions for the Elderly provide welfare and health services, primarily for the elderly who have no family or when it does not have conditions to take their care. Having in mind the fact that often the asylums are labeled by society in a prejudicial manner, this study aimed to identify and analyze the social representations of institutionalized elderly about aging and about their old condition. In this qualitative research, it was adopted the case study method. The data collection was operationalized through observation and interviews with institutionalized elderly. The study results indicated distinct social representations: some focusing on losses, in which old age was associated with abandonment, loneliness, conflict, poverty and disease, and others focusing on the gains, as the representations of old age as an active phase, propitious to amorous involvements and rest.

Keywords: Elderly. Long Term Care Institutions for the Elderly. Old age. Social Representations.

\section{Referências}

ALCÂNTARA, A. O. Velhos Institucionalizados e Família: entre abafos e desabafos. Campinas: Alínea, 2004.

ANVISA - AGÊNCIA NACIONAL DE VIGILÂNCIA SANITÁRIA. Resolução da Diretoria Colegiada - RDC/ANVISA n ${ }^{\circ} 283$, de 26 de setembro de 2005. 2005. Disponível em: <http://www.saude.mg.gov.br/atos_normativos/legislacao-sanitaria/estabelecimentos-de-saude/atencao-ao-idoso/RES_283.pdf>. Acesso em: 24 jun. 2011.

ARRUDA, A. Modernidade \& cia: repertórios da mudança. In: JESUÍNO, J. C.; MENDES, F. M. M.; LOPES, M. J. (Org.). As representações sociais nas sociedades em mudança. Petrópolis: Vozes, 2015. p. 103-127.

BARDIN, L. Análise de conteúdo. São Paulo: Edições Loyola, 2010. 
BARROS, M. M. L. Testemunho de vida: um estudo antropológico de mulheres na velhice. In: (Org.). Velhice ou Terceira Idade? Estudos antropológicos sobre identidade, memória e política. Rio de Janeiro: Editora Fundação Getúlio Vargas, 1998, p. 69-84.

BERZINS, M. A. S.; GIACOMIN, K. C.; CAMARANO, A. A. A Assistência Social na Política Nacional do Idoso. In: ALCÂNTARA, A. O.; CAMARANO, A. A.; GIACOMIN, K. C. (Org.). Política Nacional do Idoso: velhas e novas questões. Rio de Janeiro: IPEA, 2016, p. 107-133.

BULLA, L. C.; MEDIONDO, M. Z. Velhice, dependência e vida cotidiana institucional. In: CORTELLETTI, I. A.; CASARA, M. B.; HERÉDIA, V. B. (Org.). Idoso Asilado: um estudo gerontológico. 2. ed. Caxias do Sul: Educs; Porto Alegre: Edipucrs, 2010. p. 89109.

CAMARANO, A. A. Jovens e idosos nordestinos: exemplos de trocas intergeracionais? Texto para discussão n. 1031. Rio de Janeiro: Ipea, 2004.

CAMARANO, A. A.; BARBOSA, P. Instituições de Longa Permanência para Idosos no Brasil: do que se está falando? In: ALCÂNTARA, A. O.; CAMARANO, A. A.; GIACOMIN, K. C. (Org.). Política Nacional do Idoso: velhas e novas questões. Rio de Janeiro: Ipea, 2016. p. 479-514.

CAMARANO, A. A.; KANSO, S. As instituições de longa permanência para idosos no Brasil. Revista Brasileira de Estudos de População, Rio de Janeiro (RJ), v. 27, n. 1, p. 233-235, 2010.

- Perspectivas de crescimento para a população brasileira: velhos e novos resultados. Texto para discussão n. 1426. Rio de Janeiro: Ipea, 2009.

CAMARANO, A. A.; KANSO, S.; MELLO, J. L.; CARVALHO, D. F. As Instituições de Longa Permanência para Idosos no Brasil. In: CAMARANO, A. A. (Org.). Cuidados de longa duração para a população idosa: um novo risco social a ser assumido? Rio de Janeiro: Ipea, 2010. p. 187-212.

CAMARGOS, M. C. S.; SANTOS, M. C. V.; BOMFIM, W. C.; SILVA, K. R. Viver em Instituição de Longa Permanência: o olhar do idoso institucionalizado. Revista Kairós Gerontologia, São Paulo (SP), v. 19, n. 3, p. 135-150, 2016.

CAVEDON, N. R. As representações sociais circulantes no período de margem do ritual de passagem: o caso dos peritos criminais em estágio probatório. RAM - Revista de Administração Mackenzie, São Paulo (SP), v. 15, n. 2, 66-96, 2014.

Os saberes sociais produzidos no cotidiano. In: . (Org.). Representações sociais na área de gestão em saúde: teoria e prática. Porto Alegre: Dacasa, 2005. p. 11-19.

. Antropologia para Administradores. Porto Alegre: Editora da Ufrgs, 2003.

. As representações sociais dos universitários sobre o trabalho. In: ENCONTRO DA ASSOCIAÇÃO NACIONAL DE PÓS-GRADUAÇÃO E PESQUISA EM ADMINISTRAÇÃO, 23, 1999, Foz do Iguaçu. Anais... Foz do Iguaçu: Anpad, 1999. p. 1-15.

CHRISTOPHE, M.; CAMARANO, A. A. Dos asilos às Instituições de Longa Permanência: uma história de mitos e preconceitos. In: CAMARANO, A. A. (Org.). Cuidados de longa duração para a população idosa: um novo risco social a ser assumido? Rio de Janeiro: Ipea, 2010. p. 145-162.

DEBERT, G. G. A invenção da terceira idade e a rearticulação de formas de consumo e demandas políticas. In: ENCONTRO NACIONAL DA ASSOCIAÇÃO NACIONAL DE PÓS-GRADUAÇÃO E PESQUISA EM CIÊNCIAS SOCIAIS, 34., 2010, Caxambu. Anais... Caxambu: Anpocs, 2010.

. A Reinvenção da Velhice: socialização e processos de reprivatização do envelhecimento. São Paulo: Editora da Universidade de São Paulo, Fapesp, 1999. 
DEBERT, G. G.; SIMÕES, J. A. Envelhecimento e velhice na família contemporânea. In: FREITAS, E. V.; PY, L. (Ed.). Tratado de geriatria e gerontologia. 3. ed. Rio de Janeiro: Guanabara Koogan, 2011. p. 1571-79.

FERREIRA, A. J.; GOULART, D. Convivendo em um mundo tecnológico. In: TERRA, N. L. et al. (Org.). Envelhecimento e suas múltiplas áreas do conhecimento. Porto Alegre: Edipucrs, 2010. p. 103-108.

FERREIRA, J. M.; CUNHA, N. C. V.; MENUT, A. Z. C. Qualidade de Vida na Terceira Idade: um estudo de caso no SESC Alagoas. In: ENCONTRO NACIONAL DA ASSOCIAÇÃ̃O NACIONAL DE PÓS-GRADUAÇÃO E PESQUISA EM ADMINISTRAÇÃO, 32., 2008, Rio de Janeiro. Anais... Rio de janeiro: Anpad, 2008. p. 1-18.

FIGUEIREDO, M. D.; CAVEDON, N. R. A Invisibilidade dos Idosos: o Estigma Imputado aos Mais Velhos e suas Implicações em Centro Comercial de Porto Alegre. In: ENCONTRO DE GESTÃO DE PESSOAS E RELAÇÕES DE TRABALHO, 2., 2009, Curitiba. Anais... Curitiba: Anpad, 2009. p. 1-16.

FRAQUELLI, Â. A. A relação entre autoestima, autoimagem e qualidade de vida em idosos participantes de uma oficina de inclusão digital. In: TERRA, N. Luiz. et al. (Org.). Envelhecimento e suas múltiplas áreas do conhecimento. Porto Alegre: Edipucrs, 2010. p. 119-125.

GOFFMAN, E. Manicômios, Prisões e Conventos. 7. ed. São Paulo: Perspectiva, 2003.

GOMES, R. Análise e interpretação de dados de pesquisa qualitativa. In: MINAYO, M. C. S. (Org.). Pesquisa Social: teoria, método e criatividade. 28. ed. Petrópolis: Vozes, 2011. p. 79-108.

GROISMAN, D. Asilos de Velhos: passado e presente. Estudos Interdisciplinares sobre o Envelhecimento, Porto Alegre (RS), v. 2, p. 67-87, 1999.
HENDY, S. Longevity: will we enjoy a long life or will ageism spoil it? Toronto - Canadá: International Federation on Ageing, 2015. Disponível em: <http://www.ifa-fiv.org/Blog/ page/7/> Acesso em: 15 fev. 2016.

HERÉDIA, V. B. M.; CORTELLETTI, I. A.; CASARA, M. B. Institucionalização do Idoso: identidade e realidade. In: CORTELLETTI, I. A.; CASARA, M. B.; HERÉDIA, V. B. M. (Org.). Idoso Asilado: um estudo gerontológico. 2. ed. Caxias do Sul: Educs; Porto Alegre: Edipucrs, 2010. p. 15-62.

JODELET, D. Representações Sociais: um domínio em expansão. In: (Org.). As representações sociais. Rio de Janeiro: Eduerj, 2001. p. 17-44.

. La representación social: fenómenos, concepto y teoria. In: MOSCOVICI, S. (Org.). Psicologia Social: pensamiento y vida social. v. 2. Barcelona: Paidós, 1986. p. 469-494.

JOVCHELOVITCH, S. Vivendo a vida com os outros: intersubjetividade, espaço público e representações sociais. In: GUARESCHI, P. (Org.). Textos em Representações Sociais. 12. ed. Petrópolis: Vozes, 2011. p. 53-72.

KELLY, L. T. S.; RIBAS, J. R.; COSTA, I. S. A. Atividades Física, Educativa e de Dança: um Estudo dos Valores dos Consumidores Idosos. In: ENCONTRO NACIONAL DA ASSOCIAÇÃO NACIONAL DE PÓS-GRADUAÇÃO E PESQUISA EM ADMINISTRAÇÃO, 34., 2010, Rio de Janeiro. Anais... Rio de Janeiro: Anpad, 2010. p. 1-22.

LOCATELLI, P. A. L. As representações sociais sobre a velhice e os reflexos nos processos de gestão de pessoas de uma Instituição de Longa Permanência de Porto Alegre. 2012. Dissertação (Mestrado em Administração) - Universidade Federal do Rio Grande do 
Sul (Ufrgs), Escola de Administração, Porto Alegre, 2012.

LOCATELLI, P. A. P. C.; CAVEDON, N. R. As representações sociais sobre a velhice na perspectiva dos usuários de uma instituição de longa permanência. In: ENCONTRO INTERNACIONAL DE CIÊNCIAS SOCIAIS, 3., 2012, Pelotas. Anais... Pelotas: Eics, 2012. p. 1-16.

LOCATELLI, P. A. P. C.; OLIVEIRA, J. S.; CAVEDON, N. R. A construção do Sentido de Envelhecimento para os Assistentes Sociais: uma abordagem contextualista das emoções a partir do cotidiano de trabalho. Revista de Ciências da Administração, Florianópolis (SC), v. 16, n. 38, p. 77-92, 2014.

LOPES, R. G. C. Imagem e autoimagem. In: NERI, A. L. Idosos no Brasil: vivências, desafios e perspectivas na terceira idade. São Paulo: Editora Fundação Perseu Abramo, Edições Sesc SP, 2007. p. 141-152.

MARKOVÁ, I. Ética na teoria das representações sociais. In: JESUÍNO, J. C.; MENDES, F. M. M.; LOPES, M. J. (Org.). As representações sociais nas sociedades em mudança. Petrópolis: Vozes, 2015. p. 80-102.

MARQUES, J. R. "De homem-só a gestor": o significado da gestão nas representações sociais dos membros-coordenadores do MP-RS. 2012. Dissertação (Mestrado em Administração) - Universidade Federal do Rio Grande do Sul (Ufrgs), Faculdade de Administração, Porto Alegre, 2011.

MINAYO, M. C. S. O conceito de representações sociais dentro da Sociologia Clássica. In: GUARESCHI, P.; JOVCHELOVITCH, S. (Org.). Textos em Representações Sociais. 12. ed. Petrópolis: Vozes, 2011. p. 73-92.

MOTTA, F. M. Velha é a Vovozinha: identidade feminina na velhice. Santa Cruz do Sul: Edunisc, 1998.

NERI, A. L. Atitudes e preconceitos em relação à velhice. In: Idosos no Brasil: vivências, desafios e perspectivas na terceira idade. São Paulo: Editora Fundação Perseu Abramo, Edições Sesc SP, 2007. p. 33-46.

NOVAES, M. H. Psicologia da Terceira Idade: conquistas possíveis e rupturas necessárias. 2. ed. Rio de Janeiro: NAU, 1997.

NUNES, V. P. C. Envelhecimento: olhando-se no espelho da vida, através da inclusão digital. In: TERRA, N. L. et al. (Org.). Envelhecimento e suas múltiplas áreas do conhecimento. Porto Alegre: EDIPUCRS, 2010, p. 109-117.

PAPALÉO NETTO, M. Estudo da velhice: histórico, definição de campo e termos básicos. In: FREITAS, E. V.; PY, L. (Ed.). Tratado de geriatria e gerontologia. 4. ed. Rio de Janeiro: Guanabara Koogan, 2016. p. 03-13.

O estudo da velhice: histórico, definição do campo e termos básicos. In: FREITAS, E. V.; PY, L. (Eds.). Tratado de geriatria e gerontologia. 3. ed. Rio de Janeiro: Guanabara Koogan, 2011. p. 03-13.

PASCHOAL, S. M. P. Qualidade de vida na velhice. In: FREITAS, E. V.; PY, L. (Eds.). Tratado de geriatria e gerontologia. 3. ed. Rio de Janeiro: Guanabara Koogan, 2011. p. 99-106.

ROSA, T. E. C.; BARROSO, Á. E. S.; LOUVISON, M. C. P. Envelhecimento ativo: para onde rumar nessa invenção? In: Ve-

lhices: experiências e desafios nas políticas do envelhecimento ativo. São Paulo: Instituto de Saúde, 2013.

ROWLAND, R. Malefícios e Representações coletivas: ou seja, por que na Inglaterra as feiticeiras não voavam. Revista USP, São Paulo (SP), n. 31, p. 16-29, 1996.

SÁ, C. P. A construção do objeto de pesquisa em representações sociais. Rio de Janeiro: Uerj, 1998.

SILVA, A. R. L.; CARRIERI, A. P. A teoria das representações sociais nos estudos organizacionais. In: SOUZA, E. M. (Org.) Metodologias e analíticas qualitativas em 
pesquisa organizacional: uma abordagem teórico-conceitual. Vitória: Edufes, 2014. p. 45-58.

SOUZA, F. A. Gerontoarquitetura. In: TERRA, N. L. et al. (Org.). Envelhecimento e suas múltiplas áreas do conhecimento. Porto Alegre: Edipucrs, 2010. p. 39-48.

SOUZA, R. F.; MATIAS, H. A.; BRETAS, A. C. P. Reflexões sobre envelhecimento e trabalho. Ciência e Saúde Coletiva, Rio de Janeiro (RJ), v. 15, n. 6, p. 2835-2843, 2010.

SPINK, M. J. O estudo empírico das representações sociais. In: . O conhecimento no cotidiano: as representações sociais na perspectiva da psicologia organizacional. São Paulo: Brasiliense, 2004.

TAVARES, M. F. Trabalho e longevidade: como o novo regime demográfico vai mudar a gestão de pessoas e a organização do trabalho. Rio de Janeiro: Qualitymark Editora, 2015.

TORELLY, I. W. O. Envelhecimento ativo: uma nova concepção. In: TERRA, N. L. et al. (Org.). Envelhecimento e suas múltiplas áreas do conhecimento. Porto Alegre: Edipucrs, 2010. p. 79-82.

VALSINER, J. Hierarquias de signos: representação social no seu contexto dinâmico. In: JESUÍNO, J. C.; MENDES, F. M. M.; LOPES, M. J. (Org.). As representações sociais nas sociedades em mudança. Petrópolis: Vozes, 2015. p. 29-58.

VARGAS, L. S.; TACQUES, C. O. Um empreendimento hoteleiro voltado para o hóspede idoso do município de Gravatal: um estudo de caso. In: TERRA, N. L. et al. (Org.). Envelhecimento e suas múltiplas áreas do conhecimento. Porto Alegre: Edipucrs. 2010, p. 49-60.

VICTORA, C. G.; KNAUTH, D. R.; HASSEN, M. N. A. Pesquisa Qualitativa em Saúde. Porto Alegre: Tomo Editorial, 2000. 